\title{
Magnetic resonance imaging-guided laser interstitial thermal therapy for previously treated hypothalamic hamartomas
}

\author{
Anthony M. Burrows, MD, ${ }^{1}$ W. Richard Marsh, MD, ${ }^{1}$ Gregory Worrell, MD, PhD, ${ }^{2}$ \\ David A. Woodrum, MD, PhD, ${ }^{3}$ Bruce E. Pollock, MD, ${ }^{1}$ Krzysztof R. Gorny, PhD, ${ }^{3}$ \\ Joel P. Felmlee, PhD, ${ }^{3}$ Robert E. Watson, MD, PhD, ${ }^{3}$ Timothy J. Kaufmann, MD, ${ }^{3}$ \\ Steven Goerss, BS, ${ }^{1}$ and Jamie J. Van Gompel, MD${ }^{1}$
}

Departments of ${ }^{1}$ Neurosurgery, ${ }^{2}$ Neurology, and ${ }^{3}$ Radiology, Mayo Clinic, Rochester, Minnesota

OBJECTIVE Hypothalamic hamartomas (HHs) are associated with gelastic seizures and the development of medically refractory epilepsy. Magnetic resonance imaging-guided laser interstitial thermal therapy (MRg-LITT) is a minimally invasive ablative treatment that may have applicability for these deep-seated lesions. Here, the authors describe 3 patients with refractory HHs who they treated with MRg-LITT.

METHODS An institutional review board-approved prospective database of patients undergoing Visualase MRg-LITT was retrospectively reviewed. Demographic and historical medical data, including seizure and medication histories, previous surgeries, procedural details, and surgical complications, along with radiological interpretation of the HHs, were recorded. The primary outcome was seizure freedom, and secondary outcomes included medication reduction, seizure frequency, operative morbidity, and clinical outcome at the latest follow-up.

RESULTS All 3 patients in the multi-institutional database had developed gelastic seizures related to $\mathrm{HH}$ at the ages of 7,7 , and 9 years. They presented for further treatment at 25,28 , and 48 years of age, after previous treatments with stereotactic radiosurgery in all cases and partial hamartoma resection in one case. One ablation was complicated by a small tract hemorrhage, which was stable on postoperative imaging. One patient developed hyponatremia and experienced weight gain, which were respectively managed with fluid restriction and counseling. At the most recent follow-up at a mean of 21 months (range 1-32 months), one patient was seizure free while another had meaningful seizure reduction. Medication was reduced in one case.

CONCLUSIONS Adults with gelastic seizures despite previous treatments can undergo MRg-LITT with reasonable safety and efficacy. This novel therapy may provide a minimally invasive alternative for primary and recurrent $\mathrm{HH}$ as the technique is refined.

http://thejns.org/doi/abs/10.3171/2016.7.FOCUS16218

KEY WORDS gelastic seizures; epilepsy; laser interstitial thermal therapy; LITT; hypothalamic hamartomas

$\mathrm{H}$ YPOTHALAMIC hamartomas (HHs) are rare lesions most commonly resulting in gelastic seizures..$^{13}$ Multiple surgical options are available if the seizures are refractory to medical management, ${ }^{14}$ though damage to the hypothalamus and seizure recurrence rates are significant concerns with open surgery ${ }^{17}$ or stereotactic radiosurgery (SRS).$^{20}$ Less invasive means of ablation or disconnection, including SRS or radiofrequency thermal coagulation, offer less potential damage to the hypothalamus but suffer from the disadvantages of a prolonged time to treatment effect and lack of direct feedback during ablation, respectively. ${ }^{18}$ However, some HHs are difficult to treat with these methods, and some patients have refractory epilepsy despite these treatments.

Magnetic resonance imaging-guided laser interstitial thermal therapy (MRg-LITT) is a new option for the treat-

ABBREVIATIONS DWI = diffusion weighted imaging; $\mathrm{HH}=$ hypothalamic hamartoma; ILAE = International League Against Epilepsy; MPRAGE = magnetization-prepared rapid gradient echo; MRg-LITT = MRI-guided laser interstitial thermal therapy; SIADH = syndrome of inappropriate antidiuretic hormone secretion; SRS = stereotactic radiosurgery.

SUBMITTED May 27, 2016. ACCEPTED July 27, 2016.

INCLUDE WHEN CITING DOI: 10.3171/2016.7.FOCUS16218. 
TABLE 1. Laser ablation treatment parameters

\begin{tabular}{ccc}
\hline Case No. & Treatment $(\mathrm{W})$ & Time $(\mathrm{min})$ \\
\hline 1 & 7.5 & 2 \\
\hline 2 & 8.5 & 1.5 \\
\hline 3 & 6 & 1.5 \\
\hline & 7.5 & 1 \\
\hline
\end{tabular}

ment of $\mathrm{HH}$ and offers the potential advantage of realtime imaging of direct thermal ablation. The US Food and Drug Administration recently approved the Visualase system (Medtronic) for real-time MRg-LITT in intracranial neurosurgery. We report our experience in treating adults with persistent seizures despite previous therapy for HHs.

\section{Methods}

Institutional review board approval was obtained to maintain a prospective multi-institutional registry on the use of the Visualase MRg-LITT system in the treatment of medically refractory epilepsy beginning in 2010 . We conducted a retrospective review of the prospectively collected data, including demographic and historical medical data (seizure and medication histories, previous surgeries, procedural details, and surgical complications) as well as radiological interpretation of the HHs. The primary outcome was seizure freedom, and secondary outcomes included medication reduction, seizure frequency, operative morbidity, and clinical outcome at the latest follow-up.

All patients were referred to a multidisciplinary surgical epilepsy conference during preoperative evaluation. Surgery was performed in the intraoperative MRI suite with the patient under general anesthesia. A Leksell stereotactic head frame (Elekta) was placed after the induction of general anesthesia, and a stereotactic planning MRI study with Gd contrast was obtained. A target trajectory was planned on a computerized workstation with coordinates transferred to the frame, and the contrasted images were used to avoid cortical vessels. The Visualase 980-nm diode laser applicator was placed through a cranial bolt adapter via a twist drill bur hole and was advanced to the target. The patient was transferred to an intraoperative 1.5-T GE Signa MRI suite, and thermoablation was performed using real-time MR thermometry with a fast radiofrequency-spoiled gradient-recalled echo (GRE) pulse sequence and Visualase software to monitor tissue heating. Visualase software estimates tissue temperature from the change in phase data obtained from the GRE pulse sequence, and the software then employs the Arrhenius rate model to estimate a permanent tissue damage zone. To evaluate treatment effects and ensure maximally safe lesion coverage, we performed T2-weighted FLAIR imaging of the brain during and after therapy and post-Gd magnetization-prepared rapid gradient echo (MPRAGE) imaging. Diffusion weighted imaging (DWI) was also performed to evaluate for cytotoxic edema or infarction indicative of effective ablation.

\section{Results}

Three adult patients were referred for treatment of previously treated HHs (Tables 1 and 2). All had been diagnosed with gelastic seizures in childhood and had been treated medically, often with multiple medication trials (Table 3). The patient in Case 1 had developed a complex partial seizure disorder in childhood, and the patient in Case 3 had progressed to secondarily generalized seizures in childhood. Each patient's seizures had become medically refractory prior to surgical referral, and each had undergone SRS. The radiosurgical treatments had resulted in decreased gelastic seizure frequency in 2 patients and decreased seizure duration in another. Despite the reductions in seizure frequency or duration, the seizures were still debilitating. After multidisciplinary assessment, MRg-LITT was recommended in each of the patients. The mean interval between radiosurgery and MRg-LITT was 39 months (range 28-60 months).

Surgery was undertaken with treatment duration and power as outlined in Table 1. Laser ablation was conducted at 2 adjacent stations or locations in Cases 1 and 2 and was judged sufficient at 1 station in Case 3. The ablation volume on postoperative imaging corresponded well with the planning volume. Surgical trajectories are depicted in Figs. 1-3. The patient in Case 3 developed a small tract hematoma during ablation; thus, the power was adjusted down. Follow-up CT showed no further enlargement 2 days later (Fig. 3). Mean length of hospital stay was 3 days (range $2-5$ days). Following hospital discharge, the patient in Case 2 developed hypothalamic symptoms including hyponatremia due to syndrome of inappropriate antidiuretic hormone secretion (SIADH), which was treated with temporary fluid restriction. There were no long-term neurological complications from surgery in any of the 3 cases during follow-up. The patient in Case 2 had mild weight gain, with a body mass index increasing from 27.5 to 33.0 over 12 months.

The mean clinical follow-up was 21 months (range 1-33 months). The long-term follow-up in Case 3 was limited despite telephone calls and postal contacts sent

TABLE 2. Patient demographics and previous treatments

\begin{tabular}{cccccc}
\hline $\begin{array}{c}\text { Case } \\
\text { No. }\end{array}$ & $\begin{array}{c}\text { Age at 1st } \\
\text { Seizure (yrs) }\end{array}$ & $\begin{array}{c}\text { Age at Presentation } \\
\text { for LITT (yrs) }\end{array}$ & $\begin{array}{c}\text { HH Diameter \& Location } \\
\text { (relative to mammillary bodies) }\end{array}$ & Previous Treatment & $\begin{array}{c}\text { Interval Btwn Previous } \\
\text { Treatments \& MRg-LITT (mos) }\end{array}$ \\
\hline 1 & 7 & 25 & $6 \mathrm{~mm}$, anterior & 15 Gy to $50 \%$ isodose line & 28 \\
\hline 2 & 9 & 48 & $10 \mathrm{~mm}$, superior & 17 Gy to $50 \%$ isodose line & 60 \\
\hline 3 & 7 & 28 & $8 \mathrm{~mm}$, anterior & $\begin{array}{c}\text { Craniotomy/resection, } 18 \text { Gy to } 50 \% \\
\text { isodose line }\end{array}$ & 30 \\
\hline
\end{tabular}


TABLE 3. Seizure outcomes and pre- versus postablative medications*

\begin{tabular}{cccccc}
\hline Case No. & Engel Class & ILAE Class & Preop Medication & FU Interval (mos) & FU Medication \\
\hline 1 & III & 4 & $\begin{array}{c}\text { Lamotrigine 250 BID, norethindrone } \\
0.35 \text { daily, gabapentin 300 TID }\end{array}$ & 28 & Lamotrigine 150 BID \\
\hline 2 & 1 & 1 & $\begin{array}{c}\text { Carbamazepine 900 BID, lamotrigine } \\
400 \text { QHS, topiramate 100 BID }\end{array}$ & 32 & $\begin{array}{c}\text { Carbamazepine 600 BID, lamotrigine } \\
400 \text { QHS, topiramate 100 BID }\end{array}$ \\
\hline 3 & $\dagger$ & $\dagger$ & $\begin{array}{c}\text { Levetiracetam 2750/day, carbamaze- } \\
\text { pine 800/day }\end{array}$ & $<1$ & $\begin{array}{c}\text { Levetiracetam 2750/day, carbamaze- } \\
\text { pine 800/day }\end{array}$ \\
\hline
\end{tabular}

$\mathrm{BID}=$ twice daily; FU = follow-up; $\mathrm{QHS}=$ at bedtime; $\mathrm{TID}=$ thrice daily.

* Doses in mg.

† Short follow-up interval limits Engel/ILAE class assignment. This patient was an international patient, and despite extensive effort to establish follow-up, we were unable to do so.

to the patient's international address. Seizure outcomes are shown in Table 3 . The patient in Case 1 had seizure freedom for 18 months but developed recurrent seizures with medication reduction and was considered to have Engel Class III and International League Against Epilepsy (ILAE) Class 4 outcomes at 28 months. The patient in Case 2 experienced seizures following medication reduction shortly after surgery but has been Engel Class I and ILAE Class 1 since 32 months' follow-up. The medication regimen remained stable in Case 3.

\section{Illustrative Case}

Case 2

A 48-year-old man presented with persistent gelastic and complex partial seizures. He had a history of head trauma at 7 years of age and a family history of epilep- sy. His gelastic seizures began when he was 9 years old and were only partially controlled, occurring daily with carbamazepine monotherapy. At the age of 36 years he developed a superimposed complex partial seizure disorder characterized by staring and oral automatisms, which were treated with additional medications. His left $\mathrm{HH}$ was treated with SRS at age 44 years, with a decrease in gelastic seizure frequency. He remained on triple antiepileptic therapy with significant fatigue and memory impairment. Ictal electroencephalography (EEG), PET-CT, and hippocampal volumes on MRI offered no precise localization. Pretreatment MRI is shown in Fig. 2A-C.

After multidisciplinary assessment, he was approved for surgery. A left middle fontal gyrus approach was used in conjunction with the steps outlined above to advance the laser cannula to the hamartoma. Two ablations were
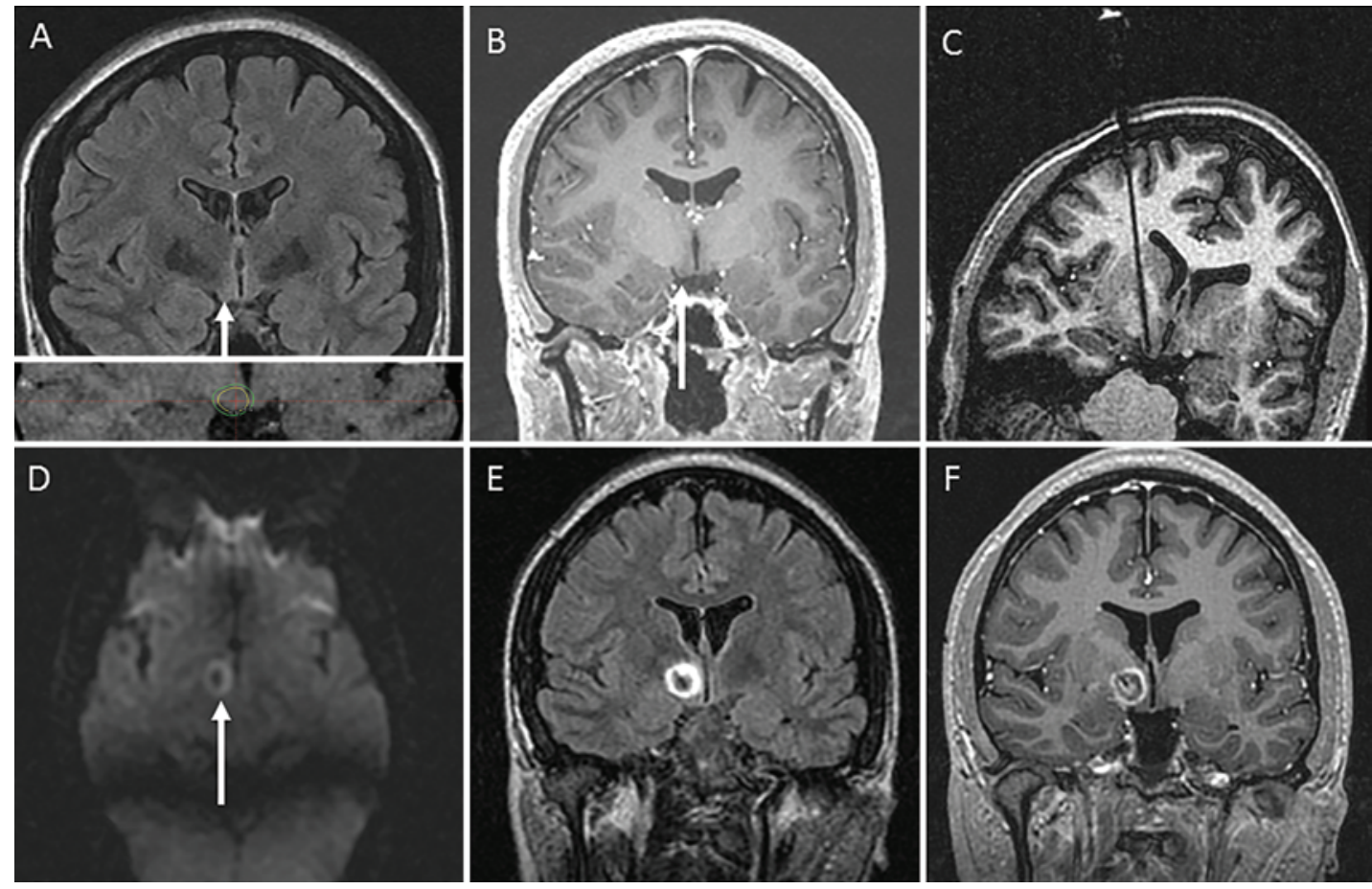

FIG. 1. Case 1. Preoperative coronal T2-weighted FLAIR (A) and T1-weighted (B) sequences demonstrate a right HH (white arrows). Inset in A shows previous radiosurgery isodose lines of 15 (inner) and 10 (outer) Gy. Pre-ablation oblique T1-weighted MPRAGE image (C) shows the laser trajectory to the hamartoma. Intra-ablation DWI sequence (D) shows lesion destruction (white arrow). Post-ablation coronal T2-weighted FLAIR (E) and postcontrast MPRAGE (F) images show destruction of the hamartoma. 

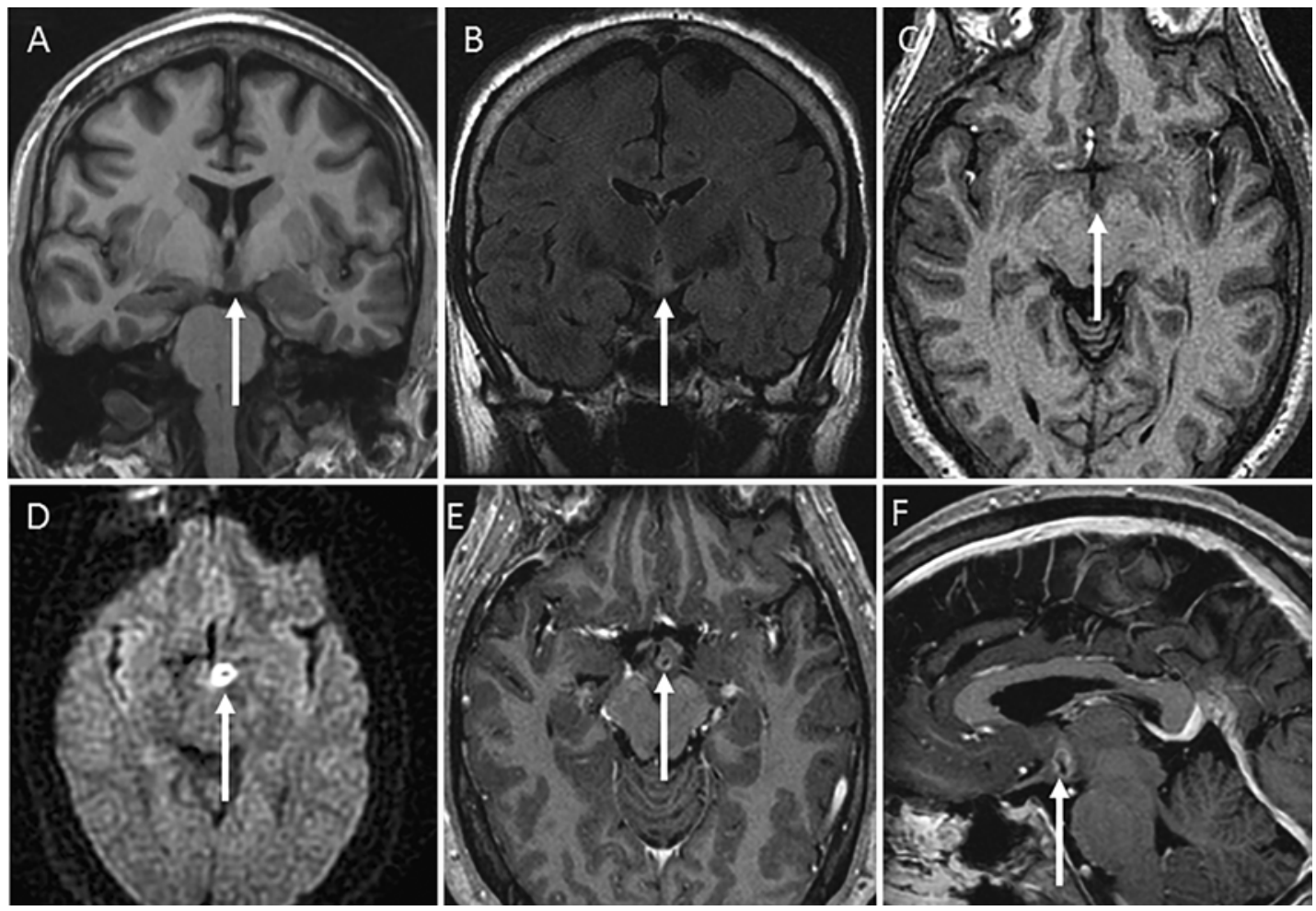

FIG. 2. Case 2. Pre-ablation coronal MR images demonstrate a left $\mathrm{HH}$ (white arrows) that is hypointense on T1-weighted MPRAGE (A) and hyperintense on T2-weighted FLAIR (B) sequences. Preoperative axial MPRAGE image (C) demonstrates the hamartoma abutting the left cerebral peduncle (white arrow). Intra-ablation DWI sequence (D) shows tissue destruction in the hamartoma (white arrow). Post-ablation MPRAGE imaging shows ablation of the hamartoma (white arrows) in the axial (E) and sagittal (F) planes.

performed: the first at $6 \mathrm{~W}$ for 90 seconds, followed by T2-weighted FLAIR imaging, which depicted mild hyperintensity; and the second at $7.5 \mathrm{~W}$ for 60 seconds. A subsequent MPRAGE study with Gd contrast depicted good coagulation of much of the hamartoma with some residual tumor abutting the cerebral peduncle (Fig. 2). The patient had transient, very mild right weakness that improved by discharge on postoperative Day 2. He developed hyponatremia on postoperative Day 4 and was treated for SIADH with temporary fluid restriction, which led to serum sodium normalization.

He had markedly reduced seizure frequency, with 5 seizures during the interval between his surgery and his 10-month follow-up. His topiramate dosage was increased, and he ultimately remained seizure free until a medication reduction trial was attempted, after which he developed another gelastic seizure. He resumed his previous regimen, and he has since remained seizure free for 13 months. His weight had increased due to an increased craving for sweets (as mentioned in Results). Unfortunately, his fatigue and cognitive slowing had not improved.

\section{Discussion}

Hypothalamic hamartomas consist of unorganized neurons and glial cells with thalamic and hypothalamic projections. ${ }^{6,13}$ They have long been associated with gelastic and other seizure types. ${ }^{13}$ There are many methods of surgical treatment for these tumors. ${ }^{14}$ Microsurgical thera- pies via the pterional and orbitozygomatic approaches have been used with adequate seizure control but a high incidence of complications. ${ }^{1,16}$ Transcallosal interforniceal approaches have been reported as well, ${ }^{7,22}$ although some groups have noted that older patients can experience memory impairment following this approach..$^{15}$ Transventricular endoscopic resection and disconnections have also been performed when feasible. ${ }^{21,24}$ Stereotactic radiosurgery offers the possibility of minimal trauma to the hypothalamus but lower rates of long-term seizure control. ${ }^{11,20}$ Radiofrequency ablations (under MRI guidance) are another option with excellent epileptic results..$^{10}$ Nonetheless, some hamartomas are not particularly amenable to these treatments or are refractory to them. Further, approach-related morbidity is significant in many of these approaches and may be abated by MRg-LITT.

In this initial experience in treating adults harboring refractory HHs with MRg-LITT for persistent and refractory gelastic seizures, we demonstrated reasonable safety. No major surgical complications were seen. Further, one patient experienced an Engel Class I and ILAE Class 1 outcome, ${ }^{4}$ and medication reduction or stability was seen in the other 2 patients, respectively. Hypothalamic symptoms occurred in 1 patient postprocedurally but were mild, consisting of weight gain and transient hyponatremia. Although the long-term outcomes are not yet known, clearly the instantaneous feedback afforded in real time by MRI of the ablation and the detailed anatomical im- 

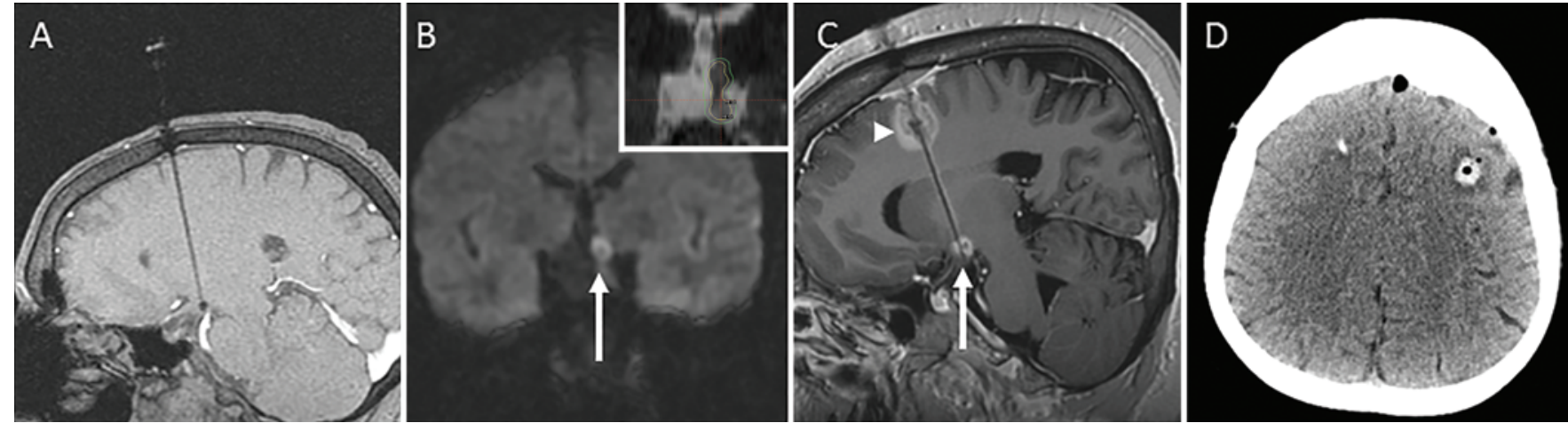

FIG. 3. Case 3. Oblique spoiled gradient sequence (A) demonstrates the trajectory to the left $\mathrm{HH}$. Intra-ablation DWI sequence (B) demonstrates destruction of the hamartoma (white arrow) with previous radiosurgery with 18-Gy (inner) and 10-Gy (outer) isodose lines shown in the inset. Post-ablation oblique MPRAGE image (C) shows destruction of the hamartoma (white arrow) as well as a small subdural and intraparenchymal hematoma (white arrowhead). Postoperative Day 2 axial CT (D) shows a small tract hemorrhage on the left and a previously placed shunt catheter on the right.

aging are intrinsic advantages to this approach. The anatomical locations of the HHs in the current study's patients limited the microsurgical and endoscopic approaches, and the older patient ages at presentation limited our use of the interforniceal approach. Radiosurgery was attempted in all of the patients but did not demonstrate efficacy after a 2-year interval despite early and promising results. Radiofrequency ablation was considered but was deemed inferior to the real-time imaging advantage of MRg-LITT.

The real-time and immediate feedback provided by the imaging in MRg-LITT is the major advantage offered by this technology over other ablative therapies for deep lesions. ${ }^{12}$ Magnetic resonance imaging guided-LITT employs thermal energy generated by a diode laser and transmitted to surrounding tissues. Precise laser applicator placement can be ensured by intraoperative MRI. Realtime MR thermometry depicts tissue heating and suggests spatial localization of coagulation zones as the treatment is performed, allowing for tailored therapy with adaptations to results during one treatment session. Early reports of MRg-LITT have indicated preliminary safety and efficacy in the treatment of recurrent primary and metastatic tumors, ${ }^{2,8,9,19,23}$ mesial temporal lobe epilepsy, ${ }^{27}$ and other epileptic foci ${ }^{3,8}$ including $\mathrm{HHs}$ and periventricular nodular heterotopias. ${ }^{5,26}$ Furthermore, MRg-LITT may offer the possibility of another less invasive option for epilepsy surgery and in this case will significantly limit approachrelated morbidity. ${ }^{18,25}$ Careful approach planning is also critical to minimize morbidity, especially with hypothalamic and other deep lesions. When possible, standard stereotactic atlases, such as Schaltenbrand and Wahren's Atlas for Stereotaxy of the Human Brain, should be consulted or, if possible, overlaid with operative plans.

Curry et al. described their early experience in treating HHs with MRg-LITT in 2 children. ${ }^{3}$ Later, Wilfong and Curry provided longer follow-up on these patients and elaborated on their experience in treating patients with HHs using MRg-LITT. ${ }^{26}$ Their patients' ages ranged from 22 months to 20 years with a $90 \%$ seizure-free rate at 6 months (among 10 patients with adequate follow-up and with 1 retreatment) and no permanent surgical morbidity. Five of these pediatric patients had undergone previous methods of treatment, including SRS and microsurgical resection.

Seizure recurrence is common following $\mathrm{HH}$ treatments. Barrow Neurological Institute's large series of 157 patients treated with multiple modalities demonstrated reoperation rates as high as $13 \% .{ }^{17}$ Among patients undergoing SRS, seizure freedom and seizure frequency reduction rates (37\% and $22 \%$, respectively) were lower than those published for microsurgical and endoscopic techniques. ${ }^{20}$ Wilfong and Curry suggested that retreatment with MRgLITT can be safe and effective for pediatric patients with previously treated HHs. We have seen similar results in adults with persistent seizures. ${ }^{26}$

Our series has several limitations. First, the sample size is very small. Second, our clinical follow-up is short in 1 patient. Third, particularly given that MRg-LITT is a relatively new technology and the experience with it for lesions like HHs is still quite limited, there could be significant interoperator and interinstitutional technical differences. However, our findings suggest that MRg-LITT has promise for the treatment of difficult or refractory lesions such as previously treated $\mathrm{HH}$, and more experience with the procedure for $\mathrm{HH}$ would be valuable.

\section{Conclusions}

Adults with gelastic seizures despite previous treatments may undergo MRg-LITT with reasonable safety and efficacy. This novel therapy may provide a minimally invasive alternative for primary and recurrent $\mathrm{HH}$ as the technique is refined.

\section{References}

1. Abla AA, Rekate HL, Wilson DA, Wait SD, Uschold TD, Prenger E, et al: Orbitozygomatic resection for hypothalamic hamartoma and epilepsy: patient selection and outcome. Childs Nerv Syst 27:265-277, 2011

2. Carpentier A, McNichols RJ, Stafford RJ, Itzcovitz J, Guichard JP, Reizine D, et al: Real-time magnetic resonance-guided laser thermal therapy for focal metastatic brain tumors. Neurosurgery 63 (1 Suppl 1):ONS21-ONS29, 2008

3. Curry DJ, Gowda A, McNichols RJ, Wilfong AA: MR-guid- 
ed stereotactic laser ablation of epileptogenic foci in children. Epilepsy Behav 24:408-414, 2012

4. Engel J Jr: Update on surgical treatment of the epilepsies. Neurology 43:1612-1617, 1993

5. Esquenazi Y, Kalamangalam GP, Slater JD, Knowlton RC, Friedman E, Morris SA, et al: Stereotactic laser ablation of epileptogenic periventricular nodular heterotopia. Epilepsy Res 108:547-554, 2014

6. Fenoglio KA, Wu J, Kim DY, Simeone TA, Coons SW, Rekate H, et al: Hypothalamic hamartoma: basic mechanisms of intrinsic epileptogenesis. Semin Pediatr Neurol 14:51-59, 2007

7. Harvey AS, Freeman JL, Berkovic SF, Rosenfeld JV: Transcallosal resection of hypothalamic hamartomas in patients with intractable epilepsy. Epileptic Disord 5:257-265, 2003

8. Hawasli AH, Bagade S, Shimony JS, Miller-Thomas M, Leuthardt EC: Magnetic resonance imaging-guided focused laser interstitial thermal therapy for intracranial lesions: singleinstitution series. Neurosurgery 73:1007-1017, 2013

9. Hawasli AH, Ray WZ, Murphy RK, Dacey RG Jr, Leuthardt EC: Magnetic resonance imaging-guided focused laser interstitial thermal therapy for subinsular metastatic adenocarcinoma: technical case report. Neurosurgery 70 (2 Suppl Operative):332-338, 2012

10. Kameyama S, Murakami H, Masuda H, Sugiyama I: Minimally invasive magnetic resonance imaging-guided stereotactic radiofrequency thermocoagulation for epileptogenic hypothalamic hamartomas. Neurosurgery 65:438-449, 2009

11. Mathieu D, Kondziolka D, Niranjan A, Flickinger J, Lunsford LD: Gamma Knife radiosurgery for refractory epilepsy caused by hypothalamic hamartomas. Stereotact Funct Neurosurg 84:82-87, 2006

12. McNichols RJ, Gowda A, Kangasniemi M, Bankson JA, Price RE, Hazle JD: MR thermometry-based feedback control of laser interstitial thermal therapy at $980 \mathrm{~nm}$. Lasers Surg Med 34:48-55, 2004

13. Mittal S, Mittal M, Montes JL, Farmer JP, Andermann F: Hypothalamic hamartomas. Part 1. Clinical, neuroimaging, and neurophysiological characteristics. Neurosurg Focus 34(6):E6, 2013

14. Mittal S, Mittal M, Montes JL, Farmer JP, Andermann F: Hypothalamic hamartomas. Part 2. Surgical considerations and outcome. Neurosurg Focus 34(6):E7, 2013

15. Ng YT, Rekate HL, Prenger EC, Chung SS, Feiz-Erfan I, Wang NC, et al: Transcallosal resection of hypothalamic hamartoma for intractable epilepsy. Epilepsia 47:1192-1202, 2006

16. Palmini A, Paglioli-Neto E, Montes J, Farmer JP: The treatment of patients with hypothalamic hamartomas, epilepsy and behavioural abnormalities: facts and hypotheses. Epileptic Disord 5:249-255, 2003

17. Pati S, Abla AA, Rekate HL, Ng YT: Repeat surgery for hypothalamic hamartoma in refractory epilepsy. Neurosurg Focus 30(2):E3, 2011

18. Quigg M, Harden C: Minimally invasive techniques for epilepsy surgery: stereotactic radiosurgery and other technologies. J Neurosurg 121 Suppl:232-240, 2014

19. Rao MS, Hargreaves EL, Khan AJ, Haffty BG, Danish SF: Magnetic resonance-guided laser ablation improves local control for postradiosurgery recurrence and/or radiation necrosis. Neurosurgery 74:658-667, 2014
20. Régis J, Scavarda D, Tamura M, Nagayi M, Villeneuve N, Bartolomei F, et al: Epilepsy related to hypothalamic hamartomas: surgical management with special reference to gamma knife surgery. Childs Nerv Syst 22:881-895, 2006

21. Rekate HL, Feiz-Erfan I, Ng YT, Gonzalez LF, Kerrigan JF: Endoscopic surgery for hypothalamic hamartomas causing medically refractory gelastic epilepsy. Childs Nerv Syst 22:874-880, 2006

22. Rosenfeld JV, Harvey AS, Wrennall J, Zacharin M, Berkovic SF: Transcallosal resection of hypothalamic hamartomas, with control of seizures, in children with gelastic epilepsy. Neurosurgery 48:108-118, 2001

23. Sloan AE, Ahluwalia MS, Valerio-Pascua J, Manjila S, Torchia MG, Jones SE, et al: Results of the NeuroBlate System first-in-humans Phase I clinical trial for recurrent glioblastoma: clinical article. J Neurosurg 118:1202-1219, 2013

24. Stabell KE, Bakke SJ, Egge A: Cognitive and neurological sequelae after stereoendoscopic disconnection of a hypothalamic hamartoma. A case study. Epilepsy Behav 24:274278, 2012

25. Tovar-Spinoza Z, Carter D, Ferrone D, Eksioglu Y, Huckins S: The use of MRI-guided laser-induced thermal ablation for epilepsy. Childs Nerv Syst 29:2089-2094, 2013

26. Wilfong AA, Curry DJ: Hypothalamic hamartomas: optimal approach to clinical evaluation and diagnosis. Epilepsia 54 (Suppl 9):109-114, 2013

27. Willie JT, Laxpati NG, Drane DL, Gowda A, Appin C, Hao $\mathrm{C}$, et al: Real-time magnetic resonance-guided stereotactic laser amygdalohippocampotomy for mesial temporal lobe epilepsy. Neurosurgery 74:569-585, 2014

\section{Disclosures}

An unrestricted grant from the Visualase Corporation was received.

\section{Author Contributions}

Conception and design: Van Gompel, Marsh, Woodrum. Acquisition of data: Van Gompel, Burrows, Marsh, Worrell, Woodrum, Gorny, Felmlee, Watson, Kaufmann, Goerss. Analysis and interpretation of data: Van Gompel, Burrows, Worrell, Woodrum, Pollock, Gorny, Felmlee, Kaufmann. Drafting the article: Van Gompel, Burrows, Worrell, Watson. Critically revising the article: Van Gompel, Burrows, Marsh, Woodrum, Pollock, Kaufmann. Reviewed submitted version of manuscript: Van Gompel, Burrows, Marsh, Woodrum, Gorny, Felmlee, Watson, Goerss. Study supervision: Van Gompel, Marsh.

\section{Supplemental Information}

\section{Previous Presentations}

Portions of this paper were presented in poster form at the 2015 American Association of Neurological Surgeons Annual Scientific Meeting held in Washington, DC, on May 2-6, 2015.

\section{Correspondence}

Jamie J. Van Gompel, Department of Neurosurgery, Mayo Clinic, 200 First St. SW, Rochester, MN 55905. email: vangompel. jamie@mayo.edu. 